\title{
Implementation of tidal turbines in MIKE 3 and Delft3D models of Pentland Firth \& Orkney Waters
}

\author{
S Waldman ${ }^{\mathrm{a}, *}$, S Bastón ${ }^{\mathrm{a}}$, R Nemalidinne ${ }^{\mathrm{b}}$, A Chatzirodou $^{\mathrm{c}}, \mathrm{V}$ Venugopal $^{\mathrm{b}}$, \\ J Side ${ }^{\mathrm{a}}$ \\ ${ }^{a}$ Heriot-Watt University, Back Road, Stromness, Orkney, KW16 3AW, UK \\ ${ }^{b}$ Institute for Energy Systems, School of Engineering, University of Edinburgh, Edinburgh, \\ EH9 3JL, UK \\ ${ }^{c}$ Energy 83 Environment Group, Zienkiewicz Centre for Computational Engineering, College \\ of Engineering, Swansea University, Singleton Park, Swansea, SA2 8PP, UK
}

\begin{abstract}
As part of the Terawatt project, two regional-scale hydrodynamic models of the Pentland Firth \& Orkney waters were developed using unaltered commerciallyavailable software (MIKE 3 and Delft3D), in order to investigate the suitability of such software for predicting the effects of tidal stream energy development. Realistic scenarios for tidal energy extraction were implemented in each, and the predictions of the models with and without turbines compared. Similar predictions were made of depth-averaged current speed (spatial correlation of $R^{2}=0.95$ ), but bed stress in one model was more than double that in the other due to the use of different values for bed resistance. The effects of energy extraction are consistent between the models at a regional scale but show considerable local differences. We conclude that these model codes are suitable for broad-scale assessment of the effects of energy extraction but that caution, and more detailed survey data, is required at fine scales.
\end{abstract}

Keywords: regional modelling, energy extraction, MIKE 3, Delft3D

\section{Introduction}

Tidal energy convertors (TECs) remove energy from the environment, for conversion into electricity. As a consequence, the kinematics of tidal currents will be altered and some change in the hydrodynamics of the local environment is inevitable. Regulatory authorities are required to understand the extent of such effects on specific receptors in order to determine whether they are acceptable, and hence the prediction of these effects is essential to any consenting process that will approve tidal energy developments (Side et al., 2016).

While direct analytical techniques can approximate the hydrodynamics of simple channels with idealised energy extraction (e.g. Garrett and Cummins,

*Corresponding author. email: simon@simonwaldman.me.uk 
2005, 2007), a numerical modelling approach is required to predict the effects of realistic TECs in real-world sea areas such as the Pentland Firth and Orkney Waters (PFOW). Tidal currents have previously been simulated in the NorthWest European shelf seas using a number of different regional-scale models including SUNTANS, ADCIRC, Fluidity, ROMS, and MIKE (Baston and Harris, 2010; Draper et al., 2013; Martin-Short et al., 2015; Neill et al., 2014; Fairley et al., 2015). A recent review article by Neill et al. (2017) gave a good summary of recent work on the tidal resource of Scotland using the results of models such as these.

The TeraWatt project (Side et al., 2016), of which this work formed a part, aimed to identify best practice methods for predicting the regional-scale effects of tidal energy extraction which could be used by industry and regulators. The project received strong guidance from industrial stakeholders that only unaltered, reputed and well-tested commercial software could be used for this work if the results were to be accepted by investors. We were advised of a perception amongst investors that open source code cannot be trusted unless backed with the reputation of a trusted commercial organisation. Many of the academic codes mentioned above were deemed unsuitable on this basis, and based on guidance from industry two three-dimensional modelling suites were selected: MIKE 3 by DHI ${ }^{1}$, and Delft3D-Flow by Deltares ${ }^{2}$. Both of these packages are already in extensive use commercially.

Demonstration models of the PFOW area were developed separately in the two suites by different teams, according to the capabilities of each. No attempt was made to match parameters between the models, as this approach would be unavailable to a developer or consultancy with access to only one software package. Rather, an emphasis was placed upon evaluating the differences, in both methods and results, between the two systems. Others in TeraWatt are developing methods for predicting changes to benthic ecology, which will be published separately, and time series of current speed and sea bed shear stress predicted by these models were provided to them as input data.

\subsection{Overview}

The structure of this paper is as follows: First we give a brief description of the area of the study and of the available observational data. Next, the two models are described, their predictions without turbines compared, and the differences discussed. Details are then given of the implementation of tidal turbines in each model, and predictions of the effects of the turbines are examined. Finally, we discuss implications for industry and regulators.

\subsection{Description of the area of the study}

Orkney is a group of islands separated from the north coast of Scotland by the Pentland Firth. The Pentland Firth is approximately $20 \mathrm{~km}$ long and

\footnotetext{
${ }^{1}$ http://www.mikepoweredbydhi.com/

${ }^{2}$ https://www.deltares.nl/en/software
} 


\begin{tabular}{llrr}
\hline Record type & Location & Latitude & Longitude \\
\hline Tide gauge & Wick & $58^{\circ} 26^{\prime} 28.68^{\prime \prime} \mathrm{N}$ & $3^{\circ} 5^{\prime} 5.64^{\prime \prime} \mathrm{W}$ \\
Tide gauge & Kinlochbervie & $58^{\circ} 27^{\prime} 23.80^{\prime \prime} \mathrm{N}$ & $5^{\circ} 3^{\prime} 1.30 ” \mathrm{~W}$ \\
ADCP & PF Site 1 (west) & $58^{\circ} 43^{\prime} 34.00^{\prime \prime} \mathrm{N}$ & $3^{\circ} 14^{\prime} 11.01^{\prime \prime} \mathrm{W}$ \\
ADCP & PF Site 2 (mid) & $58^{\circ} 43^{\prime} 1.02^{\prime \prime} \mathrm{N}$ & $3^{\circ} 5^{\prime} 9.02^{\prime \prime} \mathrm{W}$ \\
ADCP & PF Site 3 (east) & $58^{\circ} 40^{\prime} 13.02^{\prime \prime} \mathrm{N}$ & $2^{\circ} 58^{\prime} 35.03^{\prime \prime} \mathrm{W}$ \\
ADCP & Fall of Warness & $59^{\circ} 9^{\prime} 21.6^{\prime \prime} \mathrm{N}$ & $2^{\circ} 49^{\prime} 51.6^{\prime \prime} \mathrm{W}$ \\
ADCP & Inner Sound & $58^{\circ} 39^{\prime} 35.28^{\prime \prime} \mathrm{N}$ & $3^{\circ} 7^{\prime} 43.32^{\prime \prime} \mathrm{W}$ \\
\hline
\end{tabular}

Table 1: Table showing locations of observational data sources used in this work. Further detail may be found in the text of Section 1.3.

10-15 km wide (see Figure 1).

The tides in the area are predominantly semidiurnal, and there is a phase difference of $50-60^{\circ}$ from one side of Orkney to the other, equivalent to a time difference of approximately two hours between high water on the Atlantic and North Sea coasts (Easton et al., 2012). This results in a difference in water level across the archipelago, and thus strong currents in the Pentland Firth and other channels due to hydraulic forcing. In the constrained area between the isles of Stroma and Swona, the current speed regularly exceeds $4.5 \mathrm{~m} \mathrm{~s}^{-1}$ (UK Hydrographic Office, 1986).

In addition to the Pentland Firth, a second channel is of interest: this passes through the North Isles of Orkney and is formed of Westray Sound, the Fall of Warness, and Stronsay Sound.

\subsection{Available observational data}

Limited observational data is publicly available for the area. Observations from four sources were used for calibration and validation purposes, the locations of which are described in Table 1. The locations of the ADCPs are shown on Figure 1 (the tide gauges at Wick and Kinlochbervie lie outside the bounds of this map). Tide gauge data was obtained from the Delft3D Dashboard utility (van Koningsveld et al., 2013). Data at the three Pentland Firth ADCP locations was collected by Gardline in 2001 (UK Maritime \& Coastguard Agency, 2001). Visual inspection of the envelope of the springs/neaps cycle, as reported by these ADCPs, suggests that velocities at peak springs may be clipped. ADCP data at the Fall of Warness test site was purchased from EMEC. Raw data for the Inner Sound was not availible at the time of writing, but the phases and amplitudes of constituents were sourced from Gillibrand et al. (2016).

\section{The models}

\subsection{MIKE 3 model}

The three-dimensional MIKE 3 Flow Model FM (Flexible Mesh) system (2012 version) was used for this study. The MIKE FM modelling suite is based 


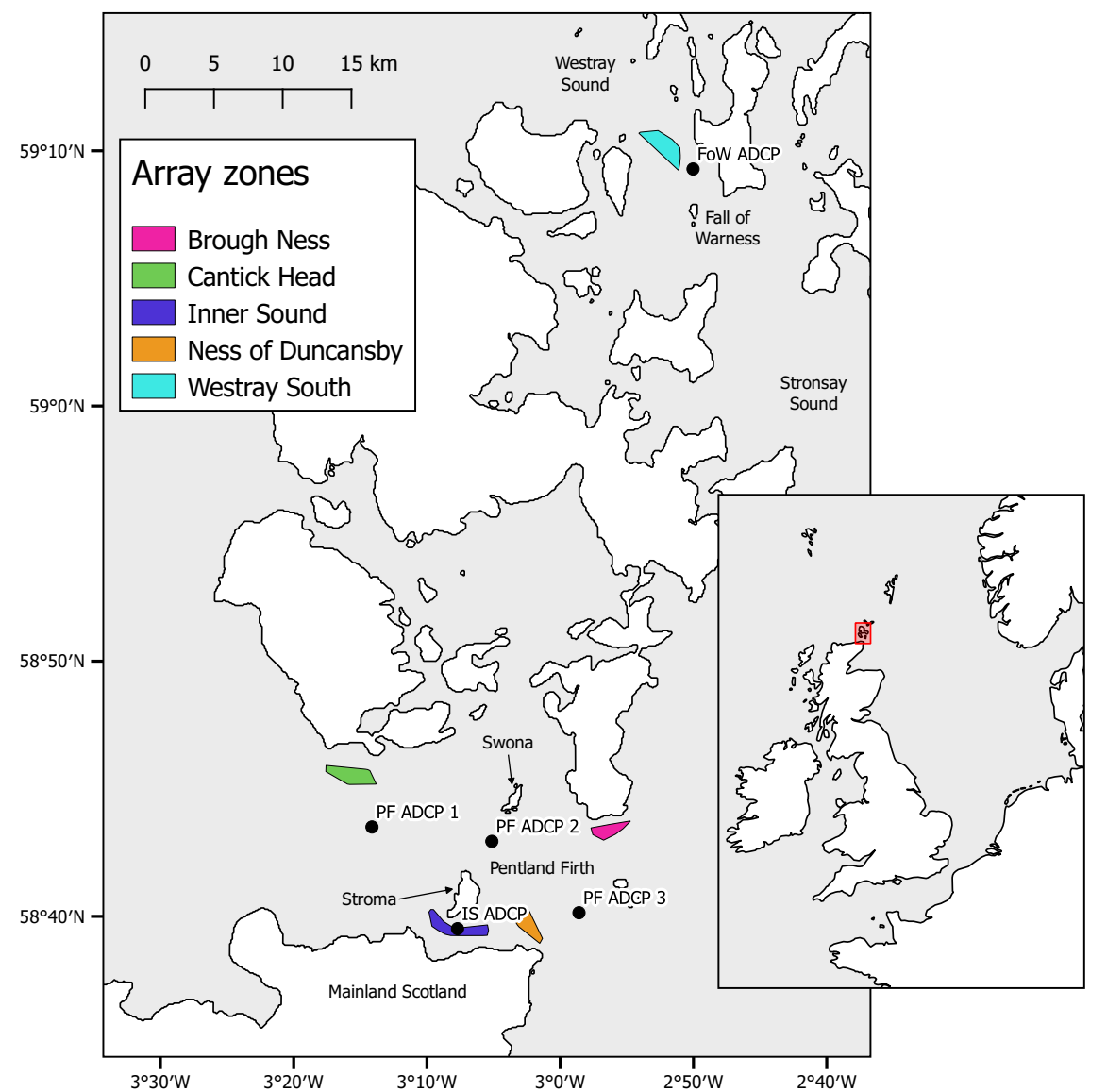

Figure 1: Map showing part of the Pentland Firth and Orkney Waters. Black points show the locations of the five ADCPs used for calibration $\&$ validation: three in the centre of the Pentland Firth (labelled PF), one in the Inner Sound (labelled IS) and one in the Fall of Warness (labelled FoW). Coloured polygons show the areas in which tidal turbines were simulated. Inset map shows location of the area within the North-West Europe region. 
on a cell centred finite volume method, with an unstructured mesh to permit accurate representation of complex coastal areas. The momentum equations used are the incompressible, Reynolds averaged form of the Navier-Stokes equations, using hydrostatic pressure and the Boussinesq assumption as to the representation of turbulence by eddy viscosity. Horizontal eddy viscosity is represented by the Smagorinsky formulation and vertical eddy viscosity is by the standard $k-\epsilon$ model. The bed resistance is specified as a quadratic drag coefficient. A comprehensive description of the model can be found in Venugopal and Nemalidinne (2014) and DHI (2012).

The model domain, shown in Figure 2, encompasses the principal high tidal flow regions of the Pentland Firth and the Fall of Warness. It features higher resolution in areas where the kinetic power density is high, and lower resolution in areas where the currents are weaker. The unstructured mesh triangles in coarse areas have a maximum characteristic length of $4000 \mathrm{~m}$; mesh triangles in the finer zones have a characteristic length of 50 to $200 \mathrm{~m}$. Ten equidistant terrain-following sigma layers are used in the vertical direction. Of the two numerical schemes offered by MIKE, the high order one was selected.

The coastline was defined throughout as an impermeable, zero normal velocity boundary, while the bottom is a no-slip, impermeable boundary with bed resistance specified by a quadratic drag coefficient of 0.01. Bathymetry was interpolated from a proprietary $20 \mathrm{~m}$ gridded dataset provided by The Crown Estate. This bathymetry is assembled from publicly available multibeam echo sounder data, described in O'Hara Murray (2015a), where available — which includes the majority of the PFOW area. Gaps in the PFOW area are filled with a commercial bathymetry product purchased from DEFRA. Parts of the model domain outside the immediate PFOW area use bathymetry from Smith and Sandwell (1997). The various data sources were merged, aligned, gridded and quality controlled by ABPmer (ABPmer, 2012) under contract to The Crown Estate.

The open boundaries were specified as clamped time-varying water levels generated using the DHI global tidal model database (Cheng and Andersen, 2010), based on the major diurnal (K1, O1, P1 and Q1) and semi-diurnal (M2, $\mathrm{S} 2, \mathrm{~N} 2$ and K2) tidal constituents at a spatial resolution of $0.25 \times 0.25^{\circ}$. This database has been validated against TOPEX/POSEIDON altimetry. The time step was automatically varied according to a target Courant number of 0.8. As there are no significant river discharges in the vicinity of the Pentland Firth, no water sources were included. The simulation was run in barotropic mode without wind forcing or wave radiation stress.

The relatively small size of this domain was necessary in order to match computational effort to the available time and hardware. It is acknowledged that placing the open boundaries further from the area of interest would be preferable. The use of clamped open boundaries is also not ideal, especially on a small domain (Adcock et al., 2011). Both MIKE 3 and Delft3D support more sophisticated radiative/transmissive boundaries, but in both cases they require external velocities, as well as elevations, to be provided. Accurate velocities over large spatial areas are not generally available in coastal areas, and so it would be 


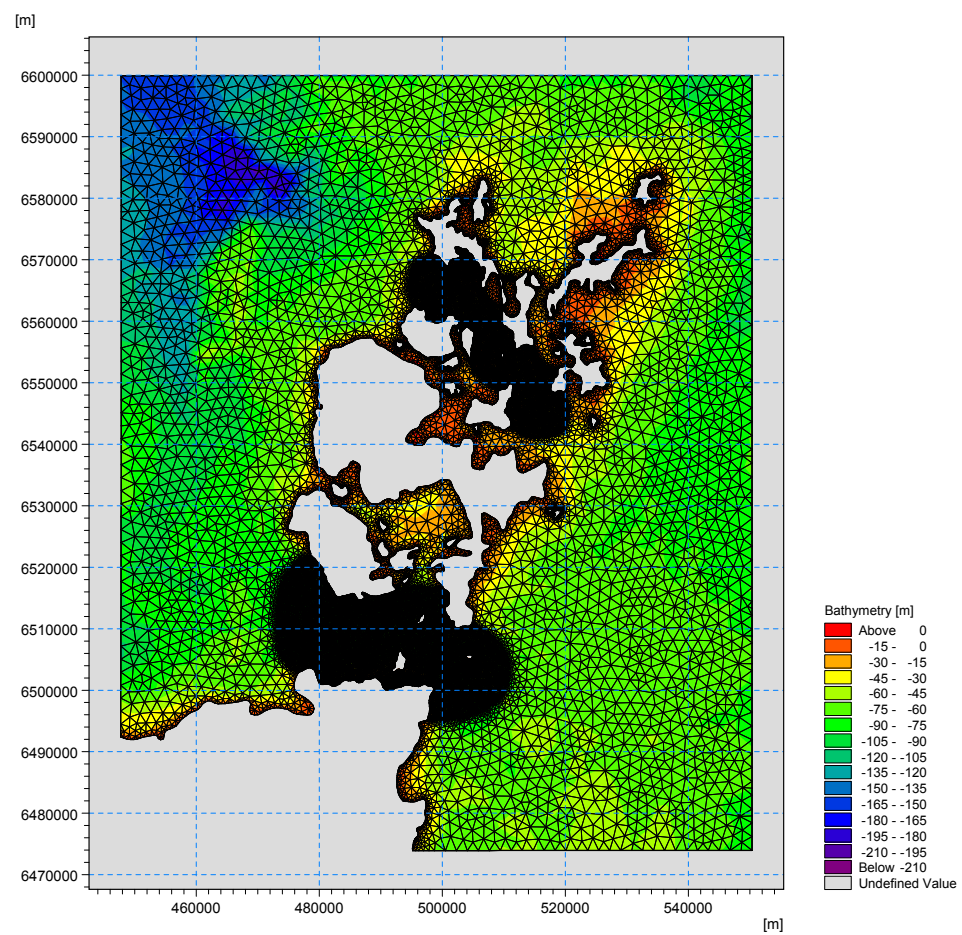

(a)

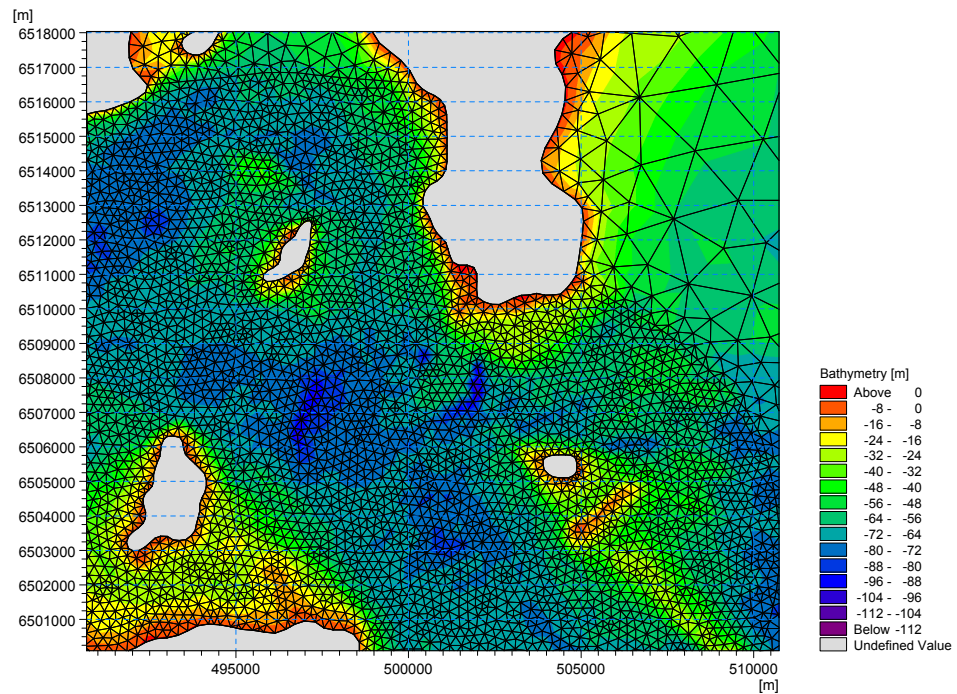

(b)

Figure 2: (a) Complete computational domain, mesh and bathymetry for MIKE 3 model; (b) detail showing Eastern part of Pentland Firth. Coordinates are in metres, referring to the UTM coordinate system zone $30 N$. 
unhelpful to suggest that commercial modellers should require this information. Some confidence that the model is not compromised by the domain size or the use of clamped boundaries may be gained by the observation that the maximum change in current speed at an open boundary as a result of including energy extraction was approx. $0.02 \mathrm{~ms}^{-1}$, or $<2 \%$ of the undisturbed value at that time and place.

\subsection{Delft3D model}

Delft3D-Flow is a finite difference code that solves the Reynolds-averaged Navier-Stokes equations under the assumption of hydrostatic pressure, using terrain-following sigma coordinates. For this work, the open source version of Delft3D with source control tag 3574 was used.

Horizontal spatial discretization is on a structured rectangular Arakawa-C grid. This is a staggered grid in which water levels are computed at grid cell centres and flow velocity components are defined at the mid-points of the cell faces to which they are perpendicular. For full details, see Deltares (2014).

Two computational grids were bidirectionally coupled: a) a coarse grid covering the North of Scotland with a domain of $254 \times 226 \mathrm{~km}$ and a horizontal resolution of $1 \times 1 \mathrm{~km}$; and b) a smaller grid covering the PFOW at a higher resolution of $200 \times 200 \mathrm{~m}$ (see Figure 3). The size of the domain was chosen to minimise the chance that any numerical instability that might arise at the boundaries would affect the area of interest. Bathymetry was interpolated from the same $20 \mathrm{~m}$ gridded dataset, provided by The Crown Estate, as was used for MIKE.

In order to reduce computation times, the outer domain was simulated in two dimensions and the inner in three. The model displayed low sensitivity to the number of vertical layers used for the inner grid; ten layers were used in this study. Horizontal eddy viscosity is provided by a large eddy simulation approach. Vertical eddy viscosity uses the $k-\epsilon$ method, although a previous study showed that this model is not sensitive to the choice of vertical turbulence scheme (Baston et al., 2013).

The open boundaries are driven by clamped time-varying surface elevation conditions, provided by the TPXO 7.2 Global Inverse Tidal Model (Egbert et al., 1994; Egbert and Erofeeva, 2002) including 13 tidal constituents at a spatial resolution of $1 / 12^{\circ}$. The model was run with a fixed time step of $25 \mathrm{~s}$, which provides for a Courant number of less than 1 .

As with the MIKE model no river sources were defined, and the model was run in barotropic mode without wind or wave forcing.

\subsection{Calibration \& validation}

The outer grid of the Delft3D model was tested against tide gauge records. No water level comparison was performed between the tide gauges and the MIKE model, because the smaller domain of this model results in the gauges location being either excluded or very close to open boundaries.

The inner Delft3D model was calibrated against ADCP records at the Fall of Warness, and the MIKE model against three ADCPs in the Pentland Firth. In 


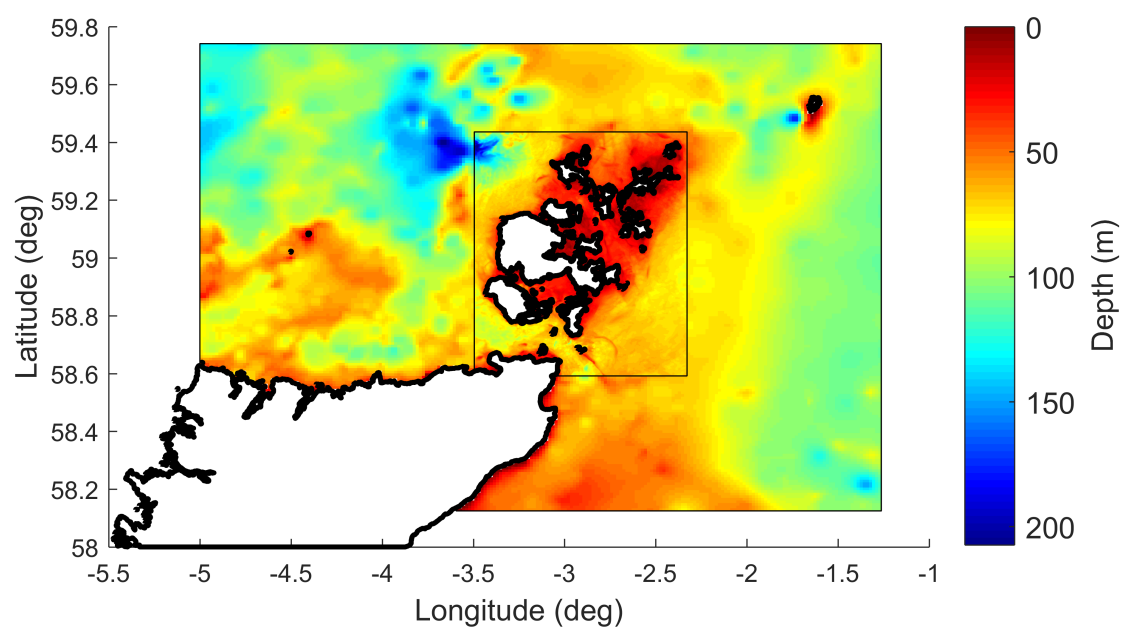

Figure 3: Map showing the Delft3D model domain. The outer grid (full coloured area) has a resulution of $1 \times 1 \mathrm{~km}$, while the inner PFOW grid (inner black box) has a resolution of $200 \times 200 \mathrm{~m}$. Colours show the model bathymetry.

both cases the bottom friction was adjusted to achieve the best match between predictions and measurements.

The use of different data sets for calibration presents a difficulty in displaying comparable validation statistics. In this section both models will be compared against the Pentland Firth ADCPs in the time domain for the period 21/09/2001 - 04/10/2001. It is acknowledged that for the MIKE model the same data are being used for calibration and validation, so the skill of the model in the area of these measurements does not necessarily imply equal skill in other areas; however, it is in this area that most of the areas of interest for tidal energy extraction are situated, and hence it is still a useful comparison to make.

In order to provide an additional check on both models, they were compared in the frequency domain with the phases and amplitudes of tidal constituents measured in the Inner Sound and published by Gillibrand et al. (2016).

See Figure 1 and Table 1 for the locations of all the ADCPs described.

\subsubsection{Time domain}

The original ADCP observation campaign recorded $4 \mathrm{~m}$ depth bins throughout the water column (UK Maritime \& Coastguard Agency, 2001). However, observations at only three deptha (different at each site) were available to this project. A ten-minute ensemble period was used in the observations. For the purposes of comparison, for each ADCP observation a mean was taken of all the model predictions that were closer in time to that observation than any other - in effect, a centred moving average.

A sensitivity analysis on the Delft3D model showed that the water levels in the inner domain were not significantly affected by the level of bed resistance in 

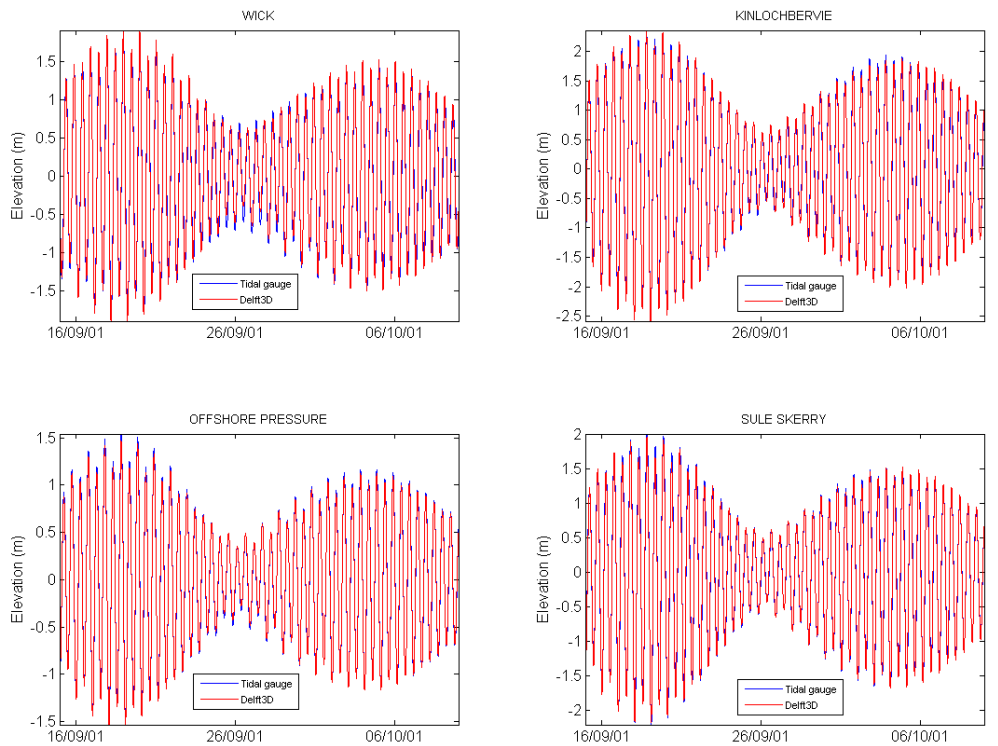

Figure 4: Comparison of water level time series for four locations on the outer (shelf) grid in Delft3D.

the outer domain. Bed resistance for the outer domain was therefore specified as a Chezy parameter of $65 \mathrm{~m}^{1 / 2} \mathrm{~s}^{-1}$, which is approximately equivalent to a "standard" classical quadratic drag coefficient of 0.0025 (Davies and Xing, 1995). Predicted water levels from the outer grid were compared with tidal gauge data from Wick, Kinlochbervie and three points from the International Hydrographic Organization (IHO) at the shelf edge, obtained using Delft Dashboard (van Koningsveld et al., 2013). Figure 4 shows comparisons of the predictions of the outer model with the water level series at four measurement sites. A good match between model output and data was found.

Validation statistics from the time-domain comparison of current velocities in both models are shown in Tables 2 and 3. For reasons of space, only the magnitudes of current speeds have been illustrated in Figures 5 and 6 .

A number of observations may be made on these statistics:

- In general there is a good match between predictions and observations, especially at Sites 2 and 3. The match at Site 1 is poorer in both models, especially in the shallow layer. As the month of the ADCP survey included heavy weather, ${ }^{3}$ this may relate to wind and wave effects near the surface.

\footnotetext{
${ }^{3}$ according to ECMWF interim reanalysis data there were four periods during the survey in which wind speeds exceeded $14 \mathrm{~m} \mathrm{~s}^{-1}$ and significant wave heights exceeded $4 \mathrm{~m}$.
} 


\begin{tabular}{|c|c|c|c|c|c|c|c|}
\hline & & \multicolumn{2}{|c|}{ Site 1} & \multicolumn{2}{|c|}{ Site 2} & \multicolumn{2}{|c|}{ Site 3} \\
\hline & & $\mathrm{u}$ & $\mathrm{v}$ & $\mathrm{u}$ & $\mathrm{v}$ & $\mathrm{u}$ & $\mathrm{v}$ \\
\hline \multirow{3}{*}{ RMSE (m/s) } & Depth 1 & 0.650 & 0.379 & 0.400 & 0.267 & 0.254 & 0.196 \\
\hline & Depth 2 & 0.386 & 0.284 & 0.324 & 0.247 & 0.214 & 0.174 \\
\hline & Depth 3 & 0.339 & 0.402 & 0.258 & 0.339 & 0.199 & 0.321 \\
\hline \multirow{3}{*}{ SI $(\%)$} & Depth 1 & 55.4 & 142 & 33.0 & 113 & 27.6 & 90.4 \\
\hline & Depth 2 & 22.4 & 41.1 & 19.9 & 38.1 & 21.1 & 47.0 \\
\hline & Depth 3 & 31.9 & 36.1 & 26.2 & 33.1 & 26.9 & 43.6 \\
\hline \multirow{3}{*}{$R^{2}$} & Depth 1 & 0.917 & 0.082 & 0.948 & 0.367 & 0.939 & 0.475 \\
\hline & Depth 2 & 0.978 & 0.949 & 0.976 & 0.936 & 0.967 & 0.915 \\
\hline & Depth 3 & 0.946 & 0.949 & 0.956 & 0.951 & 0.946 & 0.892 \\
\hline \multirow{3}{*}{$\operatorname{Bias}(\mathrm{m} / \mathrm{s})$} & Depth 1 & 0.177 & -0.183 & 0.050 & -0.218 & -0.012 & -0.124 \\
\hline & Depth 2 & 0.107 & -0.049 & 0.112 & 0.016 & 0.034 & 0.038 \\
\hline & Depth 3 & 0.008 & 0.567 & 0.018 & 0.448 & -0.007 & 0.213 \\
\hline
\end{tabular}

Table 2: Validation statistics in time domain, comparing the MIKE 3 model to observations in the Pentland Firth over a two week period in 2001. Scatter Index (SI) is defined as the RMSE divided by the mean of the observed values.

\begin{tabular}{|c|c|c|c|c|c|c|c|}
\hline & & \multicolumn{2}{|c|}{ Site 1} & \multicolumn{2}{|c|}{ Site 2} & \multicolumn{2}{|c|}{ Site 3} \\
\hline & & $\mathrm{u}$ & $\mathrm{v}$ & $\mathrm{u}$ & $\mathrm{v}$ & $\mathrm{u}$ & $\mathrm{v}$ \\
\hline \multirow{3}{*}{ RMSE (m/s) } & Depth 1 & 0.638 & 0.388 & 0.435 & 0.300 & 0.393 & 0.231 \\
\hline & Depth 2 & 0.422 & 0.306 & 0.360 & 0.255 & 0.226 & 0.155 \\
\hline & Depth 3 & 0.370 & 0.481 & 0.360 & 0.359 & 0.325 & 0.341 \\
\hline \multirow{3}{*}{ SI $(\%)$} & Depth 1 & 53.5 & 146 & 35.8 & 123 & 42.6 & 107 \\
\hline & Depth 2 & 24.5 & 44.2 & 22.2 & 39.3 & 22.3 & 41.6 \\
\hline & Depth 3 & 34.8 & 43.1 & 36.6 & 35.0 & 43.9 & 46.3 \\
\hline \multirow{3}{*}{$R^{2}$} & Depth 1 & 0.860 & 0.219 & 0.906 & 0.329 & 0.874 & 0.313 \\
\hline & Depth 2 & 0.973 & 0.935 & 0.973 & 0.923 & 0.969 & 0.926 \\
\hline & Depth 3 & 0.934 & 0.921 & 0.944 & 0.921 & 0.930 & 0.858 \\
\hline \multirow{3}{*}{$\operatorname{Bias}(\mathrm{m} / \mathrm{s})$} & Depth 1 & -0.003 & -0.181 & -0.091 & -0.242 & -0.064 & -0.164 \\
\hline & Depth 2 & 0.004 & -0.027 & 0.037 & 0.069 & -0.029 & -0.001 \\
\hline & Depth 3 & 0.186 & 0.622 & 0.151 & 0.461 & 0.026 & 0.237 \\
\hline
\end{tabular}

Table 3: Validation statistics in time domain, comparing the Delft3D model to observations in the Pentland Firth over a two week period in 2001. Scatter Index (SI) is defined as the RMSE divided by the mean of the observed values. 

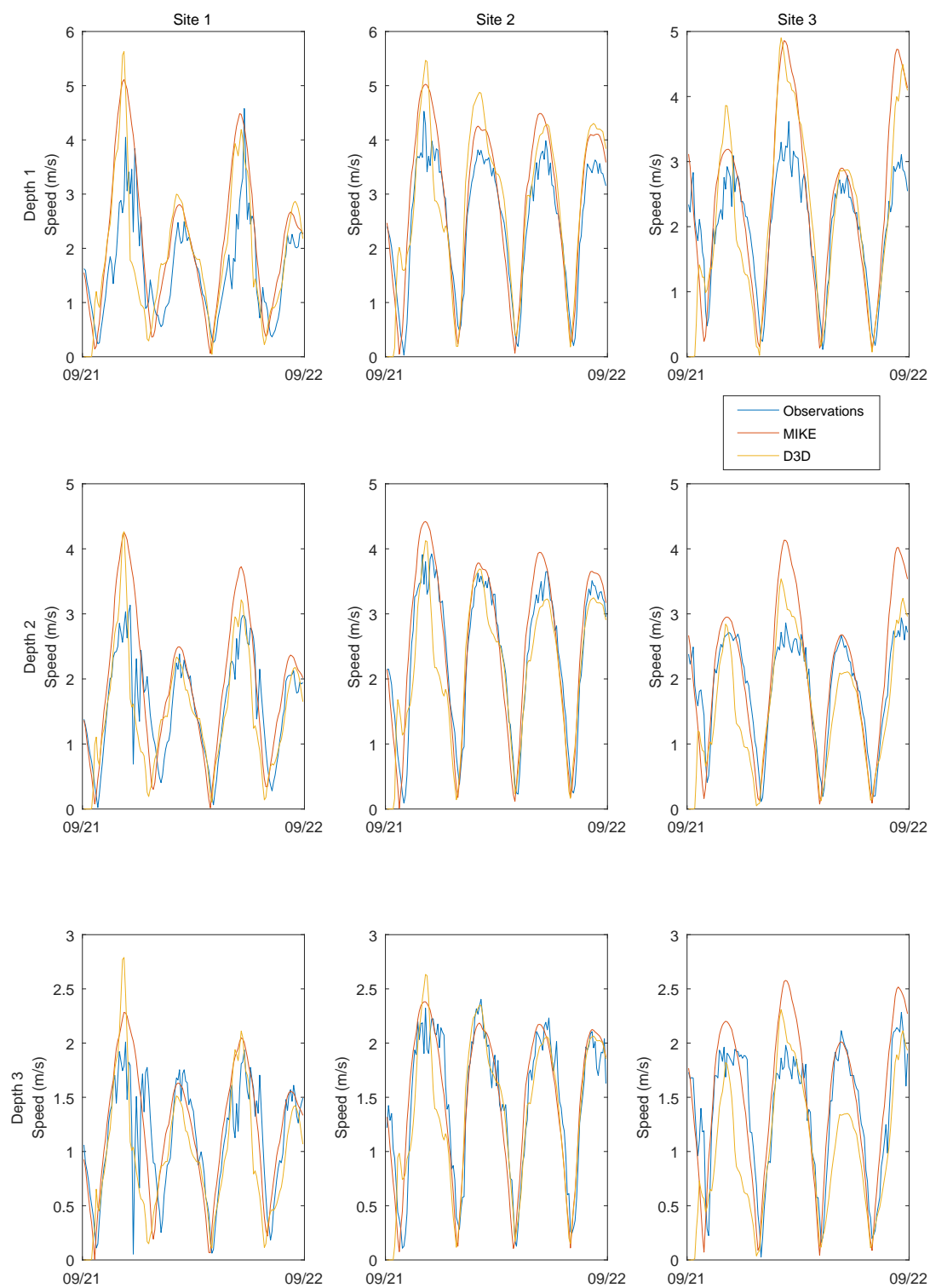

Figure 5: Time series plots of current speed, showing 24 hours at spring tides at three Pentland Firth ADCP locations at three depths. Depth 1 (top) is the shallowest and Depth 3 (bottom) the deepest. 

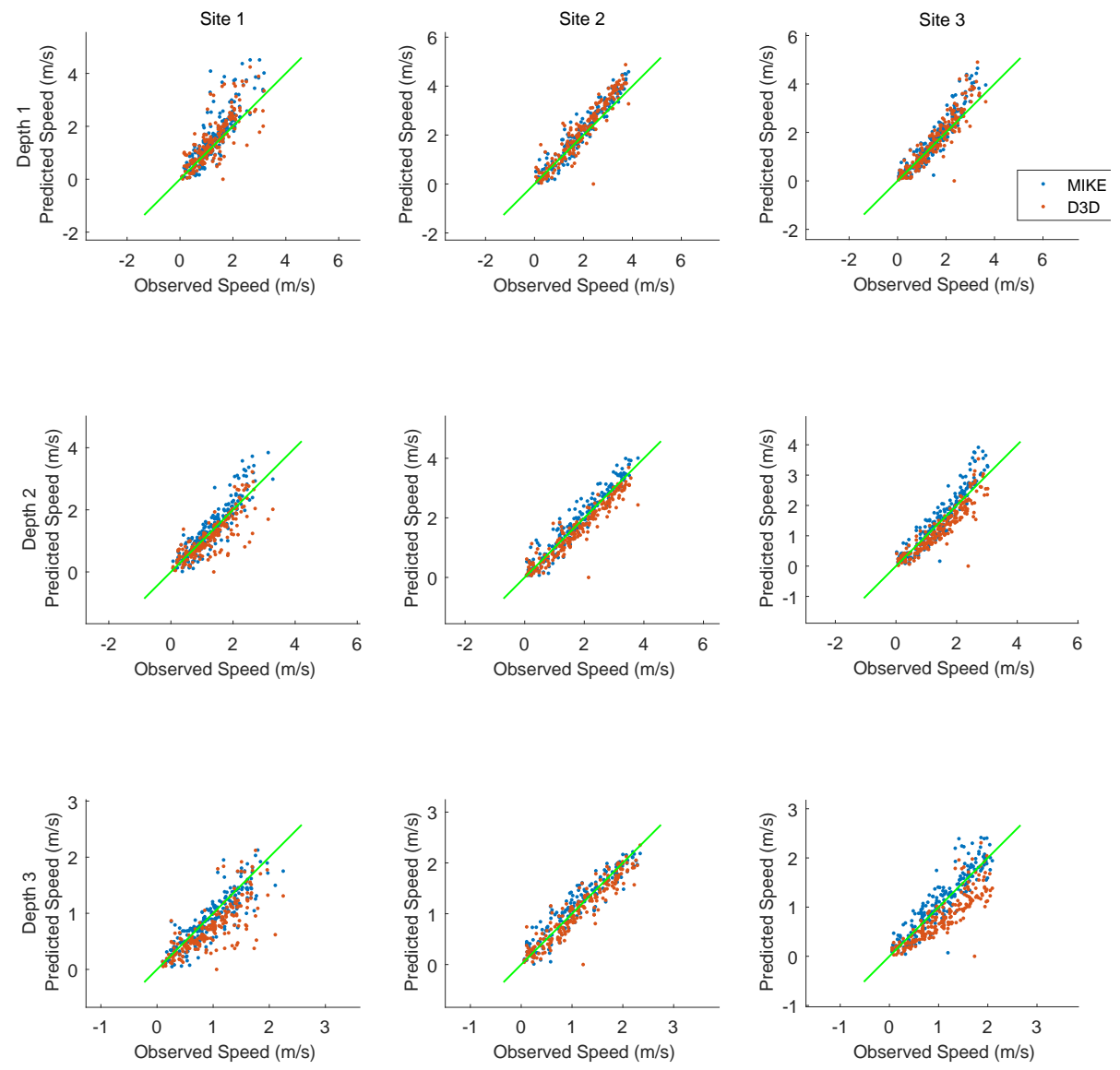

Figure 6: Scatter plots showing comparisons of both models' predictions of current speed against observations at three Pentland Firth ADCP locations, at three depths, over a two week period in 2001. To improve legibility every tenth data point is plotted. Depth 1 (top) is the shallowest and Depth 3 (bottom) the deepest. Green lines show a 1:1 relationship. 


\begin{tabular}{|c|c|c|c|c|c|c|c|}
\hline & \multicolumn{3}{|c|}{ Amplitude (m) } & \multicolumn{3}{|c|}{ Phase $\left(^{\circ}\right)$} \\
\hline & & MIKE 3 & Delft3D & Obs & MIKE 3 & Delft3D & Obs \\
\hline \multirow{3}{*}{ M2 u } & Depth 1 & 2.75 & 3.09 & 3.16 & 229 & 307 & 236 \\
\hline & Depth 2 & 2.33 & 2.96 & 2.97 & 229 & 307 & 236 \\
\hline & Depth 3 & 1.65 & 2.56 & 2.47 & 230 & 307 & 236 \\
\hline \multirow{3}{*}{$\mathrm{S} 2 u$} & Depth 1 & 1.10 & 1.18 & 1.28 & 268 & 272 & 271 \\
\hline & Depth 2 & 0.93 & 1.14 & 1.18 & 268 & 272 & 272 \\
\hline & Depth 3 & 0.66 & 0.98 & 0.97 & 269 & 272 & 271 \\
\hline \multirow{3}{*}{ M2 $v$} & Depth 1 & 0.17 & 0.09 & 0.27 & 212 & 160 & 222 \\
\hline & Depth 2 & 0.27 & 0.05 & 0.42 & 220 & 223 & 225 \\
\hline & Depth 3 & 0.25 & 0.12 & 0.58 & 222 & 284 & 226 \\
\hline \multirow{3}{*}{$\mathrm{S} 2 v$} & Depth 1 & 0.07 & 0.02 & 0.15 & 256 & 135 & 255 \\
\hline & Depth 2 & 0.12 & 0.02 & 0.20 & 262 & 226 & 259 \\
\hline & Depth 3 & 0.10 & 0.05 & 0.25 & 262 & 260 & 261 \\
\hline
\end{tabular}

Table 4: Comparison of measurements and observations in frequency domain, comparing both models to observations in the Inner Sound. Observations are from Gillibrand et al. (2016). Phases are relative to UTC. Depth 1 is the shallowest and Depth 3 the deepest.

- There is poor correlation between predictions and observations of $v$-velocities at all three sites with both models, in the shallow layer only. The depthdependence of this discrepancy suggests that it may also relate to the effects of weather, although we are unable to verify this.

- Both models overpredict the highest current speeds, especially at Sites $1 \& 3$. This is especially evident at the shallow layer, and may relate to the to the jet that is formed downstream of the constriction between Stroma and Swona. Alternatively, the observational data may be at fault; as noted in Section 1.3, there is evidence that these ADCPs experienced "knockdown" at times of peak flow.

\subsubsection{Frequency domain}

Time series of one month duration were extracted from the outputs of both models to show $u$ - and $v$-velocities at the same location and similar depths to those reported by Gillibrand et al. (2016) for their Inner Sound ADCP. The t_tide package (Pawlowicz et al., 2002) was used to perform harmonic analysis, and the amplitudes and phases of the M2 and S2 constituents were compared to those of the observations. This comparison is shown in detail in Table 4 and illustrated in Figure 7.

At the Inner Sound location, $u$-velocities are given the correct amplitude by Delft3D and are somewhat underpredicted by MIKE 3. Conversely, their phase in MIKE is close to the observations, while in Delft3D, M2 is $71^{\circ}$ (or 

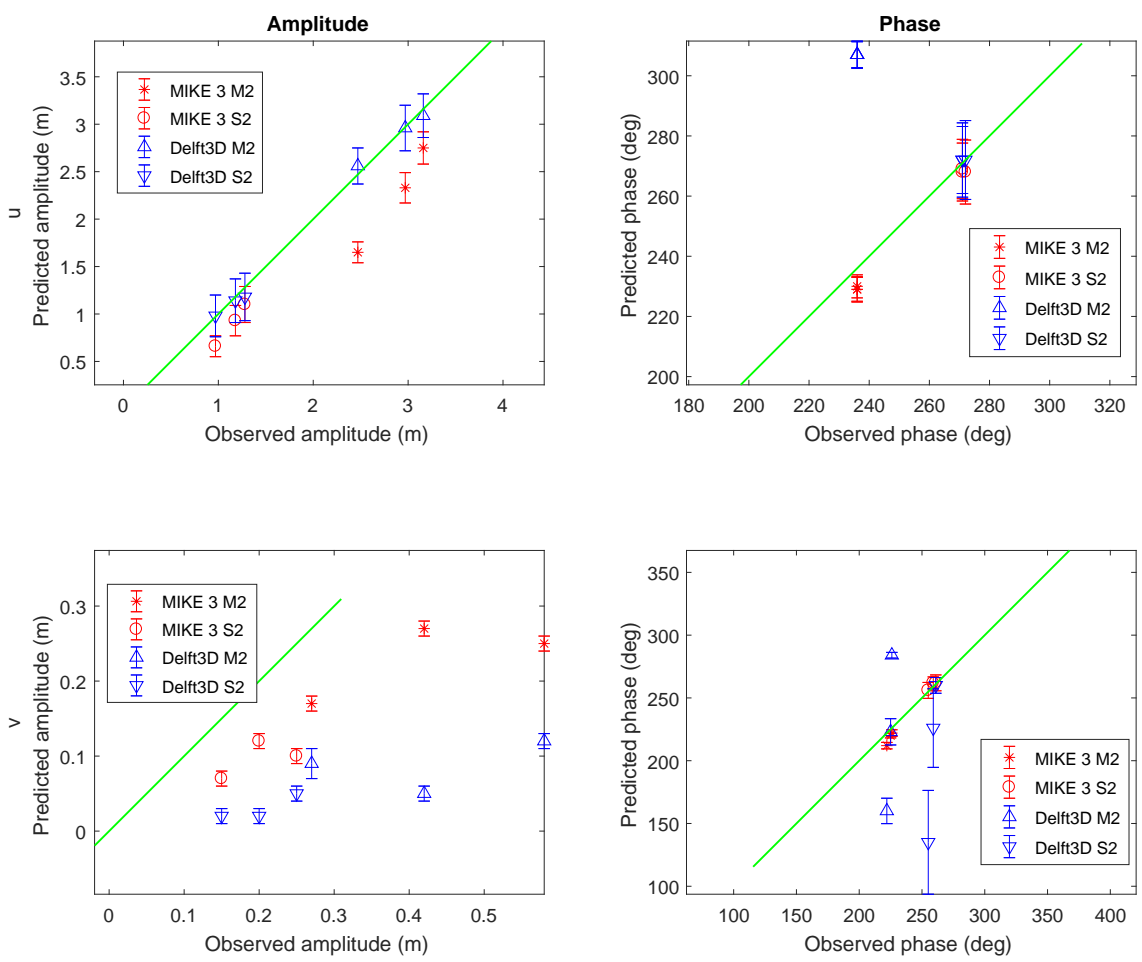

Figure 7: Plots comparing amplitude and phase of M2 and S2 constituents of $u$ (top) and $v$ (bottom) velocities between observations and predictions. Error bars show $95 \%$ confidence intervals on the harmonic analyses of the predictions; error information is not available for observations. Green lines show 1:1 relationship. 
nearly 2.5 hours) ahead. This is surprising because, while some phase difference in this direction is visible in the results for the main channel of the Pentland Firth (Figure 5), it is not of this magnitude. The lower amplitudes predicted by MIKE here - especially in the deepest layer - are also interesting, since in Figure 6 the opposite is seen.

Less importance was placed on the $v$-velocities because they are small in the Inner Sound. Both models underpredicted the amplitudes, while once again MIKE agreed well with observations as to the phases and Delft3D did not.

\section{Method for calculating bed stress}

As noted by Soulsby and Clarke (2005), there is little consensus on the best method for estimating bed shear stress $\left(\tau_{b}\right)$ from predictions of velocity. Wilcock (1996) identifies three approaches that are feasible, all of which make use of the Law Of the Wall:

$$
\frac{u_{z}}{u_{*}}=\frac{1}{\kappa} \ln \left(\frac{z}{z_{0}}\right)
$$

where $u_{z}$ is the flow velocity at a distance $z$ above the seabed, $u_{*}=\sqrt{\tau_{b} / \rho}$ where $\rho$ is the density of seawater, $\kappa$ is Von Karman's constant (equal to 0.4 ), and $z_{0}$ is the hydraulic roughness length of the seabed. This formulation makes the assumption that the vertical variation in velocity follows a logarithmic profile.

The three approaches mentioned by Wilcock are:

1. Use a single value of $u$ at the deepest available vertical location to estimate $\tau_{b}$. This has the advantage that it only assumes a logarithmic vertical profile for the part of the water column between this location and the seabed.

2. Use the depth-averaged velocity. This is the only method available for $2 \mathrm{D}$ models, but it requires the assumption of a logarithmic vertical profile for the entire water column.

3. The Law of the Wall can be rearranged into the form of an equation of a straight line. Consequently $u_{*}$, and hence $\tau_{b}$, can be estimated by plotting $\ln (z)$ against $u$ and finding the gradient of the line of best fit. This method assumes a logarithmic vertical profile, but also offers a means of assessing the validity of this assumption by looking at the quality of the fit. Unlike the other two methods, it does not require knowledge of $z_{0}$ (which is related to the intercept of the line of best fit).

A test of all three methods was performed using a short set of MIKE 3 output data in three different locations. It was found that method 1 consistently gave the lowest values of bed stress, followed by method 2 and finally method 3 . The difference in absolute values was up to a factor of three, but the proportional variation across the spatial domain was approximately constant regardless of the method used. Without any known values to compare against, we cannot judge which method produces more accurate results for bed stress; however, all appear to be similarly good for understanding its variation. 
The $R^{2}$-value for the line of best fit in method 3 was usually above 0.98 (except for short periods around slack water), which suggests that the assumption of a logarithmic vertical profile in the model outputs is a good one. However, method 3 proved to be impractical for use beyond this short test, due to the computational effort required to perform a least-squares fit for every cell at every timestep. Method 1, while appealing in that it fully uses the threedimensional capabilities of the models, has the disadvantage that the distance from the seabed at which the velocity is read varies spatially and temporally, as the vertical position of the centre of the bottom layer changes. Consequently, method 2 was adopted for the remainder of this work.

Bed stress $\overrightarrow{\tau_{b}}$ can be calculated by (from Soulsby (1997)),

$$
\overrightarrow{\tau_{b}}=\rho \vec{U}|\vec{U}|\left(\frac{0.4}{1+\ln \left(z_{0} / h\right)}\right)^{2}
$$

where $\vec{U}$ is the depth-averaged velocity and $h$ is the water depth. This formulation can be applied to the output from both models once $z_{0}$ is known, but the method of finding $z_{0}$ is different for each model due to the different ways in which they define bed resistance.

In the MIKE 3 model, bed resistance is specified as a constant quadratic drag coefficient $c_{f}$ that is applied to the bottom layer. $z_{0}$ can be derived as follows:

$$
z_{0}=\frac{z_{b}}{\exp \left(\frac{\kappa}{\sqrt{c_{f}}}\right)}
$$

where $z_{b}$ is the distance from the seabed to the centre of the bottom layer.

In the Delft3D model, bed resistance is specified as a constant Chezy value $C_{3 D}$, defined as:

$$
C_{3 D}=\frac{\sqrt{g}}{\kappa} \ln \left(1+\frac{z_{b}}{z_{0}}\right)
$$

$z_{0}$ can therefore be found by,

$$
z_{0}=\frac{z_{b}}{\exp \left(\frac{\kappa C_{S D}}{\sqrt{g}}\right)-1}
$$

\subsection{Difference in bed resistance}

Using Equations 3 and 5 we can compare the values of bed resistance in the two models. $c_{f}$ is set to 0.01 in MIKE. In the range of values used here, $c_{f} \simeq g / C_{3 D}^{2}$ (an approximation also provided by Soulsby (1997)). Using the value of $C_{3 D}=50 \mathrm{~m}^{1 / 2} \mathrm{~s}^{-1}$ set in Delft3D, this evaluates to $c_{f}=0.004$, showing that the Delft3D model uses just under half the quadratic bed resistance of the MIKE one. 


\section{Predictions without turbines}

Each model was run for a period of 32 days starting from 01/02/2012. Output from the first four days was discarded to allow for model spinup, leaving 28 days of predictions for use.

For each parameter of interest, mean predictions over this period were plotted to provide a qualitative visual comparison. These mean predictions from both models were then interpolated onto a common $100 \mathrm{~m}$ square grid covering the area of the inner Delft3D domain (see Figure 3), and the comparison between models for each parameter shown as a scatter plot. These plots are shown in in Figures 8 and 9.

It is evident that there is an excellent match between the two models on the spatial variation of each parameter across the domain, even in areas that were not used for calibration. The magnitudes of the predictions are well-matched for depth-averaged current speed. Delft3D predicts slightly faster current speeds in the bottom layer, and dramatically lower bed stress (approximately half), than MIKE.

\subsection{Discussion}

The two models, developed independently by different teams, using different software and different sources for open boundary conditions, predicted very similar relative change in values across the spatial domain in all of the parameters of interest.

Similar absolute magnitudes were predicted for depth-averaged current speed. This is as expected, because the models were calibrated using this measurement. This agreement was achieved by the use of dissimilar levels of bed resistance. Other researchers doing comparisons between models have also found it necessary to use different values for bed resistance with different software (Rahman and Venugopal, 2015).

The use of bed resistance as a tuning parameter in calibration means that its value embodies not only the actual seabed resistance, but also a correction representing all physical processes that are not explicitly modelled, as well as any inaccuracies introduced by the numerical methods used (Green and McCave, 1995). As such, it is difficult to ascribe the difference in calibrated bed resistance values to a specific cause.

The difference in bed resistance affects the vertical velocity profiles predicted by the models, hence the bottom layer speeds, and also the bed stresses. The magnitudes of these parameters differ between the models in ways that are consistent with the difference in bed resistance.

Due to the limited availability of velocity data close to the seabed, we cannot determine whether either model's predictions of these parameters is accurate. However, for the purposes of the environmental modelling in the TeraWatt project, it is spatial variation rather than absolute magnitudes that is important. On this matter the close match between MIKE 3 and Delft3D offers some confidence. 


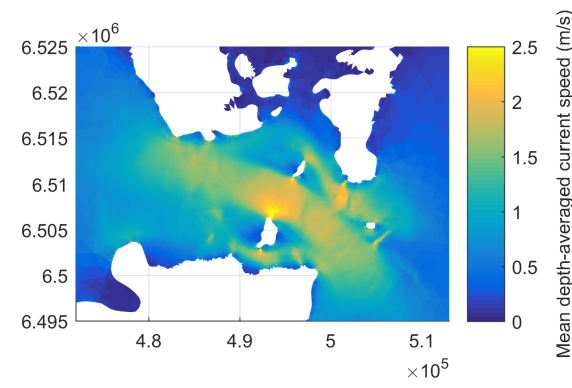

(a) Depth-averaged current speed in MIKE 3

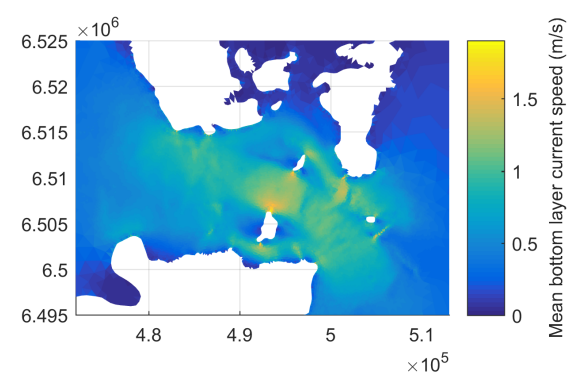

(c) Bottom layer current speed in MIKE 3

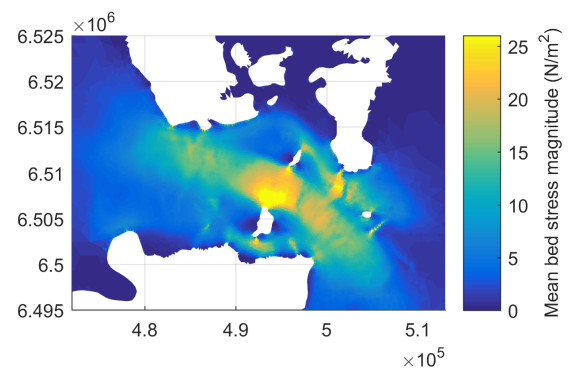

(e) Mean bed stress magnitude in MIKE 3

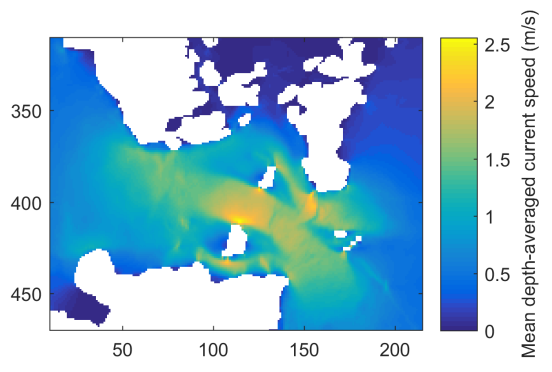

(b) Depth-averaged current speed in Delft3D

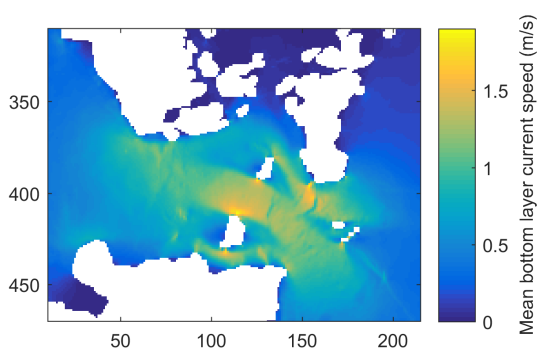

(d) Bottom layer current speed in Delft3D

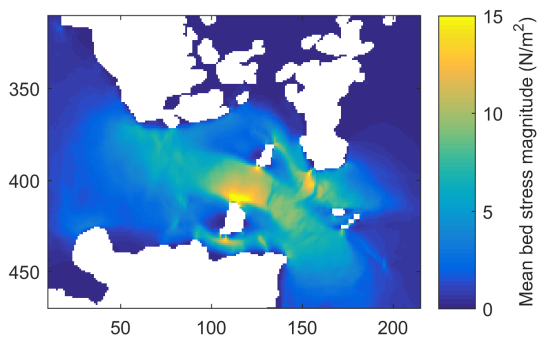

(f) Mean bed stress magnitude in Delft3D

Figure 8: Comparison of mean depth-averaged current speed, bottom layer current speed, and bed stress magnitude, over 28 days, predicted by the MIKE 3 and Delft3D models without turbines. Note the different colour scales between subfigures (e) \&6 (f). Different scales are used to show the similarity in relative spatial variation. 


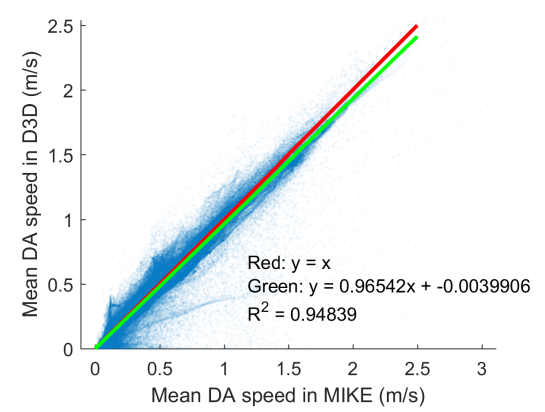

(a) Depth-averaged current speed

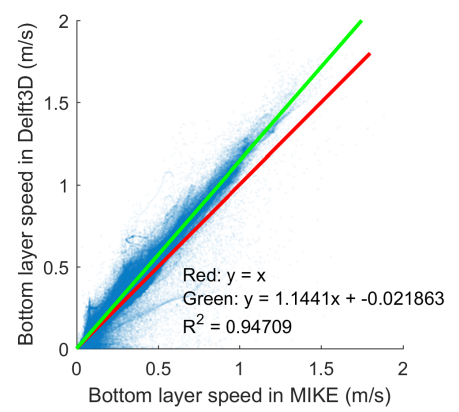

(b) Bottom layer current speed

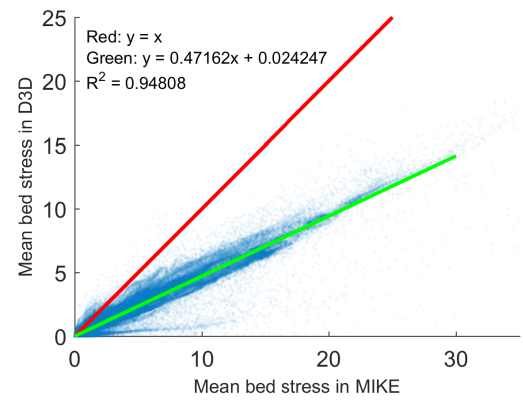

(c) Bed stress magnitude

Figure 9: Scatter plots comparing mean predictions of three parameters, over 28 days, by the two models without turbines. Plots include points from the area covered by the inner domain of the Delft3D model. Points are partially transparent to emphasise regions of high point density. Red lines indicate 1:1 relationships, while green lines show lines of best fit. 


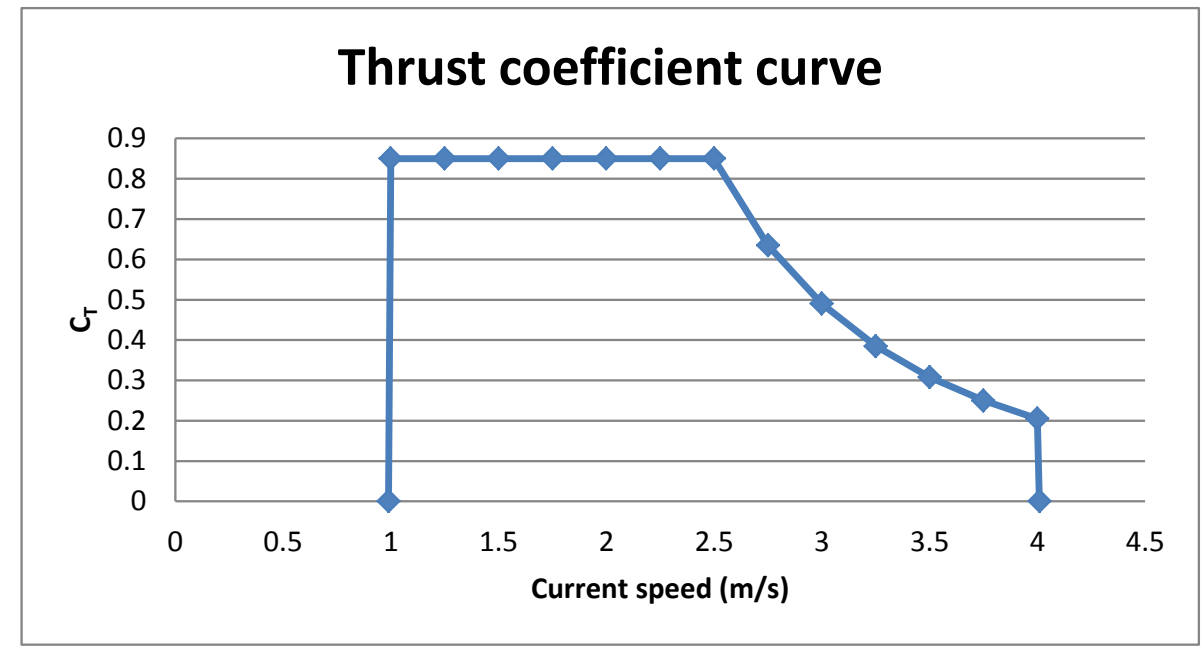

Figure 10: Generic tidal turbine thrust curve agreed with developers.

\section{Implementation of energy extraction}

\subsection{Turbine parameters $\mathcal{E}$ array layouts}

At a workshop for wave and tidal energy developers, hosted by Marine Scotland Science, parameters were agreed for a generic tidal turbine that is plausible for use in the Pentland Firth. The agreed device has a $20 \mathrm{~m}$ diameter rotor, a cut-in speed of $1 \mathrm{~m} \mathrm{~s}^{-1}$, a rated speed of $2.5 \mathrm{~m} \mathrm{~s}^{-1}$, and a cut-out speed of $4 \mathrm{~m} \mathrm{~s}^{-1}$. Its thrust coefficient curve ${ }^{4}$ is as shown in Figure 10, and the turbine would be rated at approximately $1 \mathrm{MW}$.

Realistic array layouts were developed by Marine Scotland Science from Environmental Statements submitted by developers. Five tidal array areas were identified from The Crown Estate round 1 lease zones (see Figure 1). Within these zones, turbines were arranged in rows aligned normal to the prevailing directions of flow, in positions with sufficient depth and with the highest undisturbed velocities (based on the MIKE 3 model without turbines). At the Brough Ness site, twin-rotor devices of $1 \mathrm{MW}$ per rotor are planned, so each rotor was treated as one generic device. For the detailed methodology used for the array layouts see O'Hara Murray (2015b).

A brief investigation was made into the frequency distribution of tidal speeds and directions in each of the array areas, based on the depth-averaged predictions of the MIKE 3 model. Tidal roses showing the outcome of this work are shown in Figure 11. Note that while Westray South and Cantick Head have flows which reverse direction by $180^{\circ}$, the other sites have more complex cycles

\footnotetext{
${ }^{4}$ The thrust coefficient $C_{T}$ determines the relationship between the axial flow speed and the thrust of the turbine (the retarding force that it exerts on the water), so that $F \propto C_{T} u^{2}$.
} 

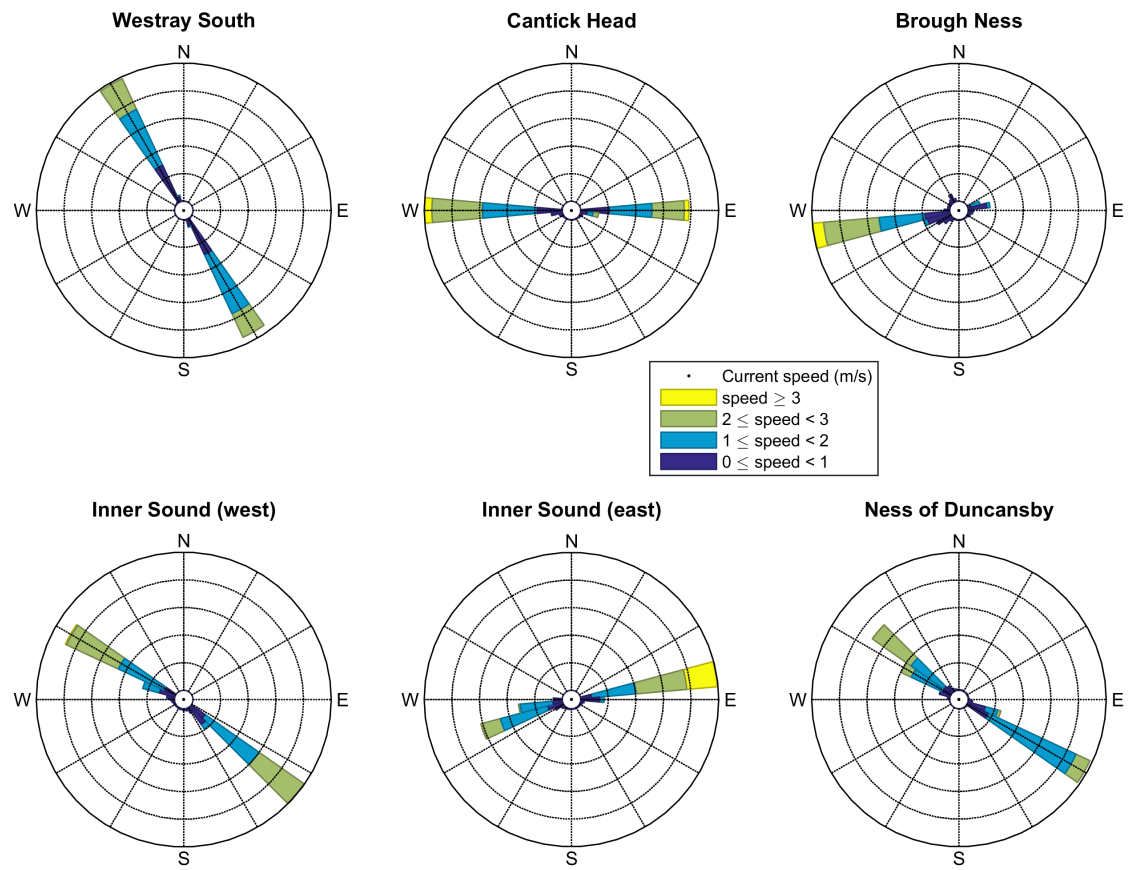

Figure 11: Tidal roses as predicted by the MIKE model from the central areas of the arrays, using depth-averaged velocities over 28 days. The distance that sectors extend from the centre of each circle indicates the frequency of flow in that direction, while colours indicate the distribution of current speed in that direction. Two roses are shown for the Inner Sound array as there is a significant change in the flow direction within the exploited area.

where the ebb does not exactly reciprocate the flood. Parts of the Brough Ness site, including the point from which the rose was generated, are affected by an eddy that causes them to experience strong tidal flow in only one direction.

\subsection{Implementation in MIKE 3}

MIKE 3 provides a built-in structure type called "Turbine". This represents a horizontal axis tidal turbine as a sub-grid object via a simple actuator disc model (DHI, 2012). The thrust coefficient $C_{T}$ is expressed as a function of current speed using a user-defined look-up table. The software allows the thrust coefficient and the resulting force to be split into components parallel and orthogonal to the turbine's axis (described by DHI as drag and lift coefficients). This facility was not used for this work; except where stated otherwise it was 
assumed that the turbines in MIKE yaw to face the flow at all times, and thus $C_{\mathrm{drag}}=C_{T}$ and $C_{\text {lift }}=0$.

Inserting tidal turbines into MIKE is simply a matter of inputting the parameters of the turbines, together with their locations, in the GUI. This process is very slow for a large number of turbines, so the task was automated using a MATLAB script (available in the TeraWatt/EcoWatt2050 code repository; see Section 8).

Supporting structures were represented as circular monopiles of $2.5 \mathrm{~m}$ diameter, extending from the seabed to the hub height. These were implemented using MIKE's built-in "Pier" structure, which is designed for bridge supports but does not require the pier to occupy the entire water column.

Strictly speaking, the value for flow velocity that MIKE uses to calculate thrust should be the "free-stream velocity", which is the velocity that the water has upstream, before it begins to feel the effects of the turbine. This value is not known to MIKE, and so instead the modelled velocity for that cell is used. The cell velocity will be lower than the free-stream velocity because of the retarding effect of the turbine, so the predicted effects of the turbine will be underestimated. This effect is negligible with large cell sizes, but becomes significant when the length of a triangle face in the mesh is below approx. 150$200 \mathrm{~m}$. Further detail on this effect is given by Kramer and Piggott (2016), and a correction that applies to simple idealised scenarios is available in Waldman et al. (2015).

\subsection{Implementation in Delft3D}

The current version of Delft3D does not include any dedicated provision for tidal turbines. Other studies have modified the code of Delft3D to incorporate TECs as momentum sinks (e.g. Ramos et al., 2013, 2014; Sánchez et al., 2014). We were advised by commercial stakeholders that investors and regulators typically require the use of well-known software as released by its vendors, without modifications or improvements. For this work, therefore, turbines were modelled by introducing a series of porous plates into the model using the unmodified code (Figure 12b). The porous plates apply a retarding force on the flow based on a paramater $c_{\text {loss }}$, which is a quadratic drag coefficient applied to the layers that the porous plate occupies.

Porous plates in Delft3D may only lie along the grid axes or at $45^{\circ}$ to them. In order to simulate turbines at arbitrary angles we created two porous plates, at right angles to each other, for each cell containing turbines, and decomposed the required force into components in the $u$ and $v$ directions before calculating the necessary porosities. The drag of each plate was determined by (taking as an example the one parallel to the $v$ axis),

$$
\begin{aligned}
c_{\text {loss- } u} & =\frac{C_{T} A_{u}}{2 \Delta y \Delta z n} \\
A_{u} & =\sum A_{t}|\sin \theta|
\end{aligned}
$$




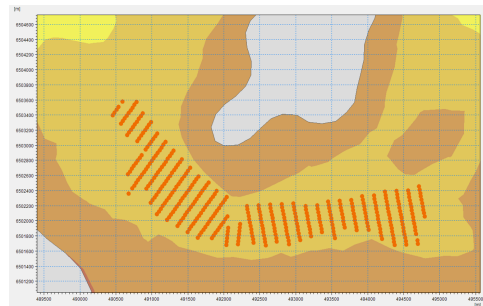

(a)

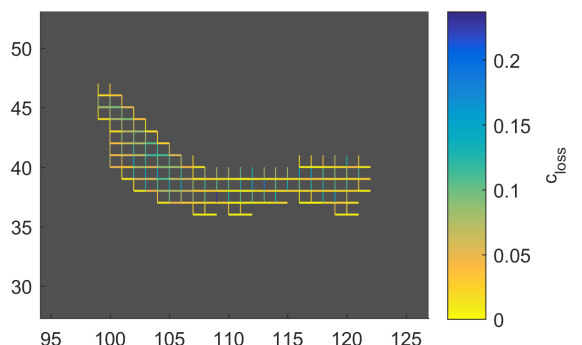

(b)

Figure 12: (a) 400 turbines in the Inner Sound, viewed through the MIKE Zero GUI; (b) The same 400 turbines represented as porous plates for Delft3D. Higher values of the $c_{\text {loss }}$ parameter, shown by bluer colours, indicate plates with higher drag.

where $C_{T}$ is the thrust coefficient for the turbine(s), $\Delta y$ is the distance between grid points along the $v$ axis, $\Delta z$ is the height of a vertical layer, and $n$ is the number of layers that the porous plate covers. $A_{u}$ represents the total area of rotor in that cell that would be visible to an observer looking along the $u$ direction; hence $A_{t}$ is the area of a turbine rotor, the sum is over all turbines in the cell, and $\theta$ is the angle between the $u$ direction and the turbine's axis.

A MATLAB script was developed to calculate the appropriate porous plate positions and porosities, and this is available in the project code repository (see Section 8). Full details, including derivation of the formula for $c_{\text {loss }}$ with and without a correction for free-stream velocity, may be found in Baston et al. (2015).

The porous plate approach in Delft3D introduces a number of limitations:

- The vertical positions of porous plates are specified in terms of the model layers that they occupy. Because the model uses 'sigma' layers, the layers intersected by a turbine rotor will change between timesteps. Delft3D does not allow porous plates to move during a simulation, so it was necessary to fix the plate as occupying the layers that are intersected by the turbine at mean sea level.

- The porosity of a porous plate cannot change over time. It is therefore not possible to realistically model turbines with variable thrust coefficients. Instead, the thrust coefficient at the rated current speed $\left(C_{T}=0.85\right)$ was fixed as a constant.

- Our method of representing arbitrary turbine orientations, together with the point above, means that turbines in Delft3D cannot yaw to follow the flow; they must instead be fixed at a single orientation. In commercial practice, a site developer would supply their modeller with orientation as well as position information. For the purposes of this work, the orientation 


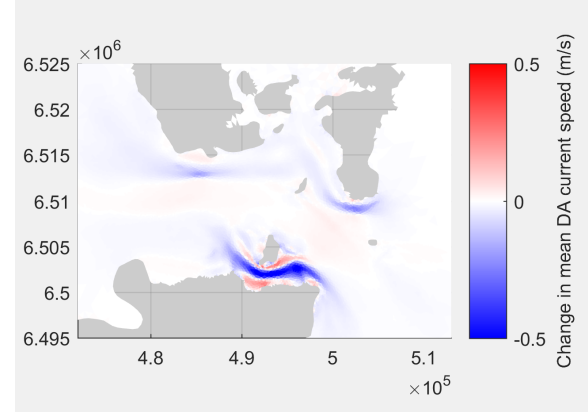

(a) Depth-averaged current speed in MIKE

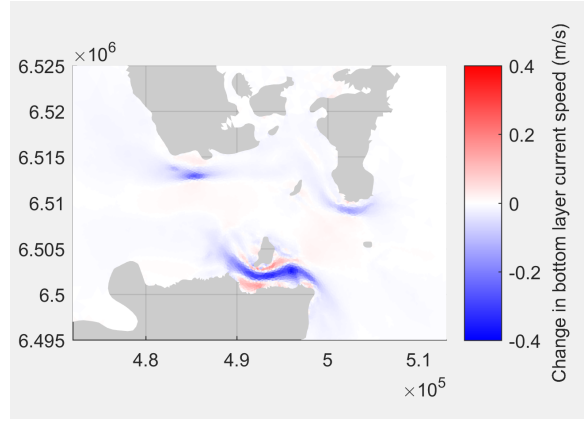

(c) Bottom layer current speed in MIKE

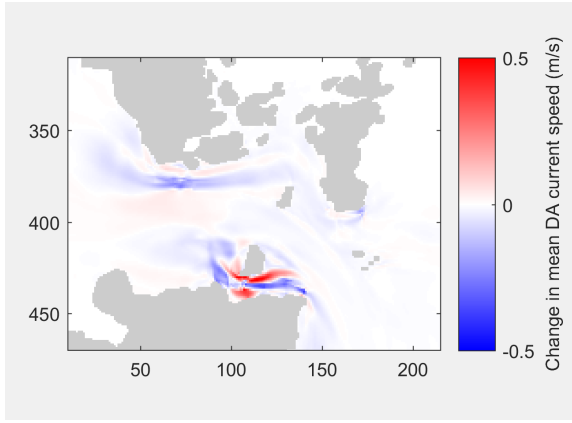

(b) Depth-averaged current speed in Delft3D

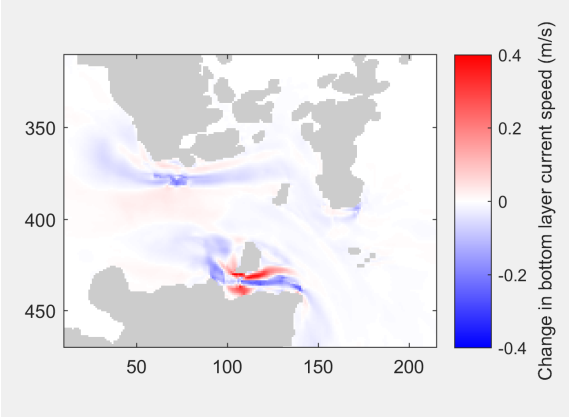

(d) Bottom layer current speed in Delft3D

Figure 13: Changes in mean current speeds over 28 days as a result of adding turbines.

of each turbine was fixed at the direction of the fastest undisturbed flow during a tidal cycle.

Supporting structures are not currently represented in the Delft3D model.

\section{Predictions with turbines}

Each model was run with and without turbines. The predictions with turbines were subtracted from those without on a per-element, per-timestep basis, to produce maps of the change that results from energy extraction.

The models show similar general features in the effect of turbines in depthaveraged current speed (Figures 13a \& 13b). There is a decrease in speed in line with TEC arrays, and an increase in speed to either side as flow diverts around the impedance of the turbines. These effects are particularly strong in the Inner Sound, where the largest array is positioned and where the flow is constrained by land boundaries on both sides. Current speeds in regions of the Pentland Firth without energy extraction are affected slightly $\left(<0.1 \mathrm{~m} \mathrm{~s}^{-1}\right)$, 


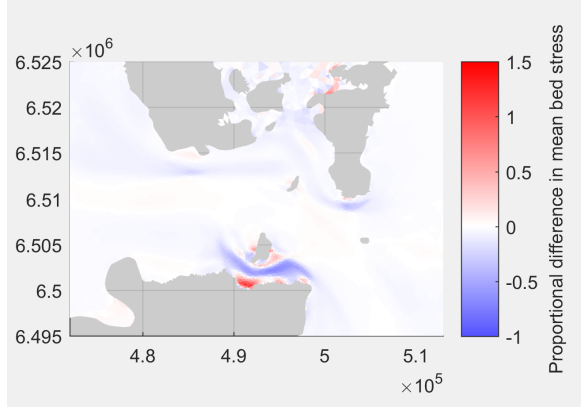

(a) $M I K E$

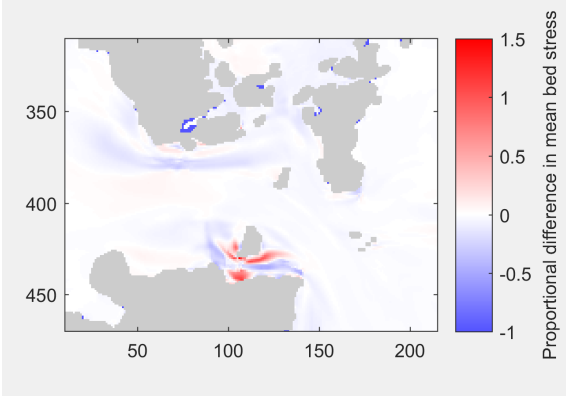

(b) Delft3D

Figure 14: Change in mean bed stress magnitude over 28 days as a result of adding turbines, expressed as a proportion of the value without turbines.

but in some areas the models disagree on whether this is a slight increase or a slight decrease.

At the Cantick Head and Westray South sites ${ }^{5}$, the magnitude of the effect of energy extraction is greater in Delft3D than MIKE. In regions distant from energy extraction, the more general effects on the flow are also greater in Delft3D. The opposite is true for the Inner Sound, Ness of Duncansby and Brough Ness sites, with a greater mean change in current speed in MIKE than in Delft3D. Additionally, at these sites there is a clear difference between the models in the spatial areas affected.

The predicted effects of energy extraction on bottom layer current speed (Figures 13c \& 13d) are similar to those on depth averaged speed, although slightly smaller in magnitude.

Because of the difference between the models in the absolute predicted values of bed stress without turbines, there is little benefit in plotting the absolute changes resulting from energy extraction. Instead, Figure 14 shows the effect of adding turbines on bed stress as a proportion of the bed stress without turbines. Viewed in this way, the effects are similar to those for depth-averaged speed. Increases in speed cause more of a difference in bed stress than decreases in speed, because of the square relationship between current speed and bed stress. The changes to bed stress are substantial; decreases of $45 \%$ and increases of up to $100 \%$ are predicted in some areas.

\subsection{Discussion}

The greater effect of turbines in Delft3D over most of the domain is consistent with the lower bed resistance used in the Delft3D model: since the natural resistance of the channel is lower, the additional resistance of the turbines is a greater proportionate change in the overall impedance in that area.

\footnotetext{
${ }^{5}$ See Figure 1 for site names; Westray South not shown in Figures $13-15$.
} 


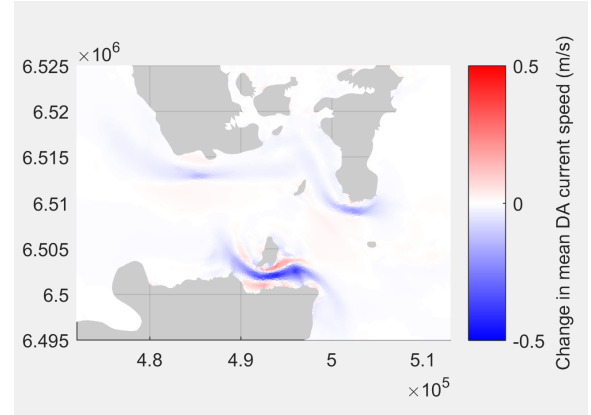

(a) MIKE with directional turbines

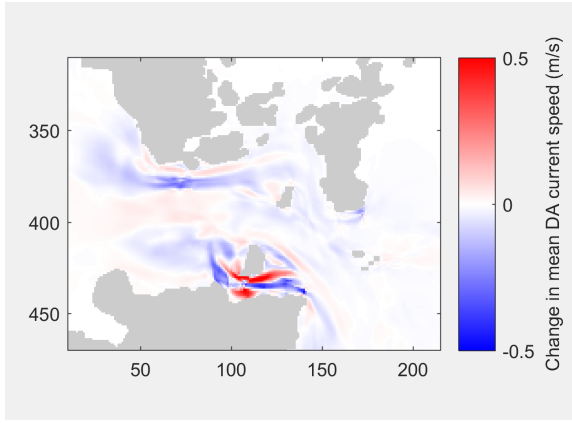

(b) Delft3D

Figure 15: Change in mean depth averaged current speed over 24 hours as a result of adding turbines. The turbines in MIKE have been specified to have a fixed orientation, resembling as closely as possible the ones in Delft3D.

Of greater interest are the three sites (Inner Sound, Brough Ness and Ness of Duncansby) where not only lesser, but spatially distinct, effects are observed in Delft3D. It was initially thought that this could be related to the inclusion of supporting structures in MIKE but not in Delft3D. However, removing the supports from the MIKE model in a test made little difference to the effects of the turbines.

The difference may, instead, be related to differences in the treatment of turbine yaw. As noted in Sections $2.1 \& 2.2$, the MIKE 3 model assumes that turbines yaw to face into the flow at all times, while the Delft3D model requires that turbines have a fixed orientation. As noted in Section 5.1, the direction of the ebb at these sites is not the reciprocal of the flood, although the differences are small. Thus, in the Delft3D model, if the turbine is oriented correctly for the flood then the ebb must reach it slightly off-axis, and hence experience a lesser force from it.

To test this hypothesis, directional turbines similar to those in Delft3D were implemented in MIKE 3 and tested in a short $24 \mathrm{~h}$ simulation. The resulting predictions (Figure 15a) show a similar magnitude of velocity deficit in line with the turbines in the Inner Sound, but still do not exhibit the same spatial variation as those of a similar $24 \mathrm{~h}$ Delft3D run (Figure 15b). In the areas of these remaining differences, both models predict eddies at a scale which can only just be resolved by the meshes used. It is possible, therefore, that the different computational meshes in the two models are simulating these eddies in slightly different locations, such that they affect the turbines differently in the two models. Without velocity data in these areas, it is not possible to know which model is more accurate. 


\section{Further discussion \& conclusions}

For discussion of the results of these specific models without and with turbines, see Sections 4.1 and 6.1 respectively. The aim of this work was not to develop the best possible tidal energy extraction models of the region of interest, but to determine how to best use existing industry-standard tools for this purpose, given their capabilities and limitations. Therefore, the emphasis of this final section is not on the specific models that were developed, but on observations of a broader scope.

\subsection{Observations on model capabilities}

MIKE 3's unstructured mesh offers greater flexibility than Delft3D's structured grid in varying the mesh density for areas of complex flow. However, this comes at a cost in computation time, for while the mesh can be sparse in outer areas, the maximum time step will tend to be set by the smallest cells. In Delft3D, higher performance has been achieved by running the outer model in two dimensions. Within the high-resolution three-dimensional area, Delft3D also runs faster.

At the time of writing, it is clear that MIKE 3 offers superior facilities for representing horizontal-axis tidal turbines. The porous plate approach used in Delft3D has been shown to be a good approximation, but requires that turbines are represented with a constant thrust coefficient and a constant orientation, and causes their vertical position to vary over time in an unrealistic way.

Since this work was conducted both DHI and Deltares have released new versions of their respective software suites. Delft3D now offers an unstructured mesh, and it is believed that a dedicated tidal turbine module is planned soon.

For some users it will be notable that MIKE is a commercial software package that must be licensed at considerable cost, while Delft3D is open source and available without payment. However, given the the perception of open source software mentioned in Section 1, if a user is aiming to satisfy an investor that the model code is trustworthy it is probable that they will use the commercial version of Delft3D, which attracts a license fee. This version uses the same underlying model code as the open source one, but benefits from the full support of Deltares.

Both models, operating as they do at a regional scale where the turbine is unresolved, can only deal in terms of the power removed from the flow by TECs. This will be greater than the power available for conversion to electricity, due to energy that is lost in mixing turbulence between the turbine wakes and the surrounding flow (Vennell, 2010). The power removed from the flow is the correct quantity to study when interested in environmental impacts, but it is interesting to note this discrepancy between the quantity being studied and the quantity that is controlled by the consenting process.

\subsection{Observations on model predictions}

Models were developed independently in MIKE 3 and Delft3D, using the facilities available in each. Following calibration the two made similar predictions 
of depth-averaged current speed across all areas of the model (including those not used for calibration), with an $R^{2}$ value of 0.95 when comparing the two models' predictions at each point of a common interpolated grid, and a ratio of Delft3D predictions to MIKE 3 predictions of 0.97 (see Figure 9). Achieving this calibration required the seabed resistance, which was used as a tuning parameter, to be set to markedly different values in the two models, resulting in the prediction of different absolute values for bed stress between the two models; the mean bed stress predicted by Delft3D was $47 \%$ of that predicted by MIKE 3. The spatial distribution of bed stress is highly correlated between the models.

The models predict broadly similar effects from energy extraction, and it is reasonable to conclude that their results may be used to inform policy as to regional-scale effects. There is some small disagreement on the magnitude of the effects on velocities, which is likely to be largely due to the difference in bed resistance mentioned above. There are significant differences in the models' predictions at a finer scale, which indicate that a model of this type should not be used for studying the effects of turbines within an array or at specific finescale locations elsewhere. For applications where such predictions are important, validation data should be collected at the points of interest. In some cases the use of a finer-scale model, backed up by this data, may be warranted. In the case of changes in bed stress, where different absolute magnitudes are predicted, the spatial variation - which is a measure of interest for the prediction of environmental impact within the TeraWatt project - was similar between the models.

The differences between our models, and the differences in model performance in different locations evident in Section 2.3, underline the importance of developing methods of setting model bed resistance from theory or measurement, rather than using it as an empirical tuning parameter, and this should be a focus for future work. It may be of benefit to vary the bed resistance spatially, if that variation is based on physics or measurement. However, the use of spatial variation without such justification must be treated with caution. By fitting to data with sufficient local freedom, nearly any model could be made to match nearly any measurements without retaining predictive power for locations or time periods other than those measured - a situation that has been described as "overcalibration" (Gerritsen et al., 1995).

Given the sensitivity of model predictions to calibration parameters, and given that errors in parameters of interest will often have square or cubic relationships to errors in current speeds (Neill et al., 2014; Filipot et al., 2014), there is a need for careful and rigorous standards for validation. This requires velocity data for the area(s) of interest which, while it may have been collected by developers, is often not publicly available.

One result of this square relationship between velocity and bed stress which means that increases in velocity have a stronger effect on bed stress than decreases do - is that the greatest changes in bed stress may be found not from the slowed flow through the turbines, but in areas of increased current speed to either side, especially where the channel is tightly constrained. This finding 
may be of relevance to environmental impact assessments.

\section{Code availability}

The MATLAB scripts mentioned in this paper are available for inspection and use at https://github.com/TeraWatt-EcoWatt2050. These automate the insertion of tidal turbines into MIKE 3 models, automate the calculation of equivalent porous plates for turbines in Delft3D models, and provide an experimental correction for the error noted in Section 5.2. We hope that they are helpful to other users of MIKE and Delft3D.

\section{Acknowledgements}

This work was funded by EPSRC grant EP/J010170/1. We thank the other members of the TeraWatt consortium for advice and feedback, and The Crown Estate and the UK Hydrographic Office for the provision of data for the project. The advice of industry representatives, in workshops and on the Steering Group, is gratefully acknowledged, as is the assistance of the Marine Alliance for Science \& Technology for Scotland (supported by Scottish Funding Council grant ref. HR09011) and Marine Scotland Science for coordinating these events. We thank David Woolf for his comments on a draft.

\section{References}

ABPmer, 2012. Pentland Firth and Orkney Waters Strategic Area : Preparation of bathymetry to support modelling studies. Technical Report R. 1963.

Adcock, T.A.A., Borthwick, A.G.L., Houlsby, G.T., 2011. The open boundary problem in tidal basin modelling with energy extraction, in: Proceedings of the 9th European Wave and Tidal Energy Conference. Southampton, UK. URL: http://www. see.ed.ac.uk/ shs/EWTEC\%202011\%20full/papers/315.pdf.

Baston, S., Harris, R., Woolf, D.K., Hiley, R.A., Side, J., 2013. Sensitivity analysis of the turbulence closure models in the assessment of tidal energy resource in Orkney, in: Proceedings of the 10th Wave \& Tidal Energy Conference, Aalborg.

Baston, S., Harris, R.E., 2010. Modelling the Hydrodynamic Characteristics of Tidal Flow in the Pentland Firth, in: 9th European Wave \& Tidal Enegy Conference.

Baston, S., Waldman, S., Side, J., 2015. Modelling energy extraction in tidal flows, rev 3.1, in: TeraWatt Position Papers. MASTS, pp. 75-107. URL: http:

//www.masts.ac.uk/media/166596/position_papers_terawatt_e-book.pdf.

Cheng, Y., Andersen, O.B., 2010. Improvement of global ocean tide models in shallow water regions, in: Altimetry for Oceans \& Hydrology OST-ST Meeting, Lisbon. URL: http://www.space.dtu.dk/english/ /media/Institutter/Space/ English/scientific_data_and_models/global_ocean_tide_model/ yongcuncheng_no_sv_1_68_45.ashx. 
Davies, A.M., Xing, J., 1995. An intercomparison and validation of a range of turbulence closure schemes used in three dimensional tidal models, in: Lynch, D.R., Davies, A.M. (Eds.), Quantitative skill assessment for coastal ocean models. American Geophysical Union, Washington DC. volume 47 of Coastal and Estuarine studies, pp. 71-95.

Deltares, 2014. Delft3D-FLOW User Manual, Hydro-Morphodynamics, Version 3.15.34158. Technical Report. URL: http:

//content.oss.deltares.nl/delft3d/manuals/Delft3D-FLOW_User_Manual.pdf.

DHI, 2012. MIKE 3 Flow Model FM Hydrodynamic Module User Guide.

Draper, S., Adcock, T.A., Borthwick, A.G., Houlsby, G.T., 2013. Estimate of the tidal stream power resource of the Pentland Firth. Renewable Energy 63, 650-657. doi:10.1016/j.renene.2013.10.015.

Easton, M.C., Woolf, D.K., Bowyer, P.A., 2012. The dynamics of an energetic tidal channel, the Pentland Firth, Scotland. Continental Shelf Research 48, 50-60. doi:10.1016/j.csr.2012.08.009.

Egbert, G.D., Bennett, A.F., Foreman, M.G.G., 1994. TOPEX/POSEIDON tides estimated using a global inverse model. Journal of Geophysical Research 99, 24821-24852. doi:10.1029/94JC01894.

Egbert, G.D., Erofeeva, S.Y., 2002. Efficient Inverse Modeling of Barotropic Ocean Tides. Journal of Atmospheric and Oceanic Technology 19, 183-204. doi:10.1175/1520-0426(2002)019<0183:EIMOBO>2 . 0. CO; 2.

Fairley, I., Masters, I., Karunarathna, H., 2015. The cumulative impact of tidal stream turbine arrays on sediment transport in the Pentland Firth. Renewable Energy 80, 755-769. doi:10.1016/j.renene.2015.03.004.

Filipot, J.F., Delafosse, C., Marzin, T., Baston, S., 2014. On the modelling errors in the tidal power assessment, in: 5th International Conference on Ocean Energy (ICOE), Halifax. URL: http://archimer.ifremer.fr/doc/00230/34114/32569.pdf.

Garrett, C., Cummins, P., 2005. The power potential of tidal currents in channels. Proceedings of the Royal Society A: Mathematical, Physical and Engineering Sciences 461, 2563-2572. doi:10.1098/rspa.2005.1494.

Garrett, C., Cummins, P., 2007. The efficiency of a turbine in a tidal channel. Journal of Fluid Mechanics 588. doi:10.1017/S0022112007007781.

Gerritsen, H., de Vries, H., Philippart, M., 1995. The Dutch Continental Shelf Model, in: Lynch, D.R., Davies, A.M. (Eds.), Quantitative Skill Assessment for Coastal Ocean Models. American Geophysical Union, Washington DC. volume 47 of Coastal and Estuarine Studies, pp. 425-467.

Gillibrand, P.A., Walters, R.A., McIlvenny, J., 2016. Numerical simulations of the effects of a tidal turbine array on near-bed velocity and local bed shear stress. Energies 9, 852. doi:10.3390/en9100852. 
Green, M.O., McCave, I.N., 1995. Seabed drag coefficient under tidal currents in the eastern Irish Sea. Journal of Geophysical Research 100, 16057.

doi:10.1029/95JC01381.

van Koningsveld, M., Damsma, T., van der Hout, R., van Wiechen, J., de Boer, G., 2013. Openearth: a knowledge management workflow for dredging projects. Terra et Aqua 131, 3-14.

Kramer, S.C., Piggott, M.D., 2016. A correction to the enhanced bottom drag parameterisation of tidal turbines. Renewable Energy 92, 385-396.

doi:10.1016/j.renene. 2016.02.022.

Martin-Short, R., Hill, J., Kramer, S., Avdis, A., Allison, P., Piggott, M., 2015. Tidal resource extraction in the Pentland Firth, UK: Potential impacts on flow regime and sediment transport in the Inner Sound of Stroma. Renewable Energy 76, 596-607. doi:10.1016/j.renene.2014.11.079.

Neill, S.P., Hashemi, M.R., Lewis, M.J., 2014. The role of tidal asymmetry in characterizing the tidal energy resource of Orkney. Renewable Energy 68, 337-350. doi:10.1016/j.renene.2014.01.052.

Neill, S.P., Vgler, A., Goward-Brown, A.J., Baston, S., Lewis, M.J., Gillibrand, P.A., Waldman, S., Woolf, D.K., 2017. The wave and tidal resource of Scotland. Renewable Energy doi:10.1016/j.renene.2017.03.027.

O'Hara Murray, R.B., 2015a. Data acquisition and processing for TeraWatt, Rev 1.1, in: TeraWatt Position Papers. MASTS, pp. 9-29. URL: http:

//www.masts.ac.uk/media/166596/position_papers_terawatt_e-book.pdf.

O'Hara Murray, R.B., 2015b. Tidal stream and wave energy array scenarios for the Pentland Firth and Orkney Waters strategic area, Rev. 2.2, in: TeraWatt Position Papers. MASTS, pp. 31-47. URL: http:

//www.masts.ac.uk/media/166596/position_papers_terawatt_e-book.pdf.

Pawlowicz, R., Beardsley, B., Lentz, S., 2002. Classical tidal harmonic analysis including error estimates in MATLAB using T_tide. Computers \& Geosciences 28, 929-937. doi:10.1016/S0098-3004(02)00013-4.

Rahman, A., Venugopal, V., 2015. Inter-comparison of 3D tidal flow models applied to Orkney islands and Pentland Firth, in: Proceedings of the 11th European Wave \& Tidal Energy Conference (EWTEC), Nantes, France.

Ramos, V., Carballo, R., Álvarez, M., Sánchez, M., Iglesias, G., 2013. Assessment of the impacts of tidal stream energy through high-resolution numerical modeling. Energy doi:10.1016/j.energy.2013.08.051.

Ramos, V., Carballo, R., Sanchez, M., Veigas, M., Iglesias, G., 2014. Tidal stream energy impacts on estuarine circulation. Energy Conversion and Management 80, 137-149. doi:10.1016/j.enconman.2014.01.027.

Sánchez, M., Carballo, R., Ramos, V., Iglesias, G., 2014. Tidal stream energy impact on the transient and residual flow in an estuary: A 3d analysis. Applied Energy 116, 167-177. doi:10.1016/j. apenergy.2013.11.052. 
Side, J., Gallego, A., James, M., Davies, I., Heath, M., Karunathra, H., Venugopal, V., Vögler, A., Burrows, M., 2016. Developing methodologies for large scale wave and tidal stream marine renewable energy extraction and its environmental impact: An overview of the TeraWatt project. Journal of Ocean \& Coastal Management doi:10.1016/j.ocecoaman.2016.11.015.

Smith, W., Sandwell, D., 1997. Measured and estimated seafloor topography. Technical Report Research Publication RP-1. World Data Center-A for Marine Geology and Geophysics. URL:

http://gcmd.nasa.gov/records/GCMD_SIO_NOAA_SEAFLOORTOPO.html.

Soulsby, R., 1997. Dynamics of Marine Sands: A Manual for Practical Applications. Thomas Telford.

Soulsby, R., Clarke, S., 2005. Bed shear-stresses under combined waves and currents on smooth and rough beds. Technical Report TR137 rev 1.0. HR Wallingford.

UK Hydrographic Office, 1986. Admiralty Tidal Stream Atlas NP209 : Orkney and Shetland Islands.

UK Maritime \& Coastguard Agency, 2001. Gardline surveys, 'Pentland Firth - tidal stream observations'. Technical Report Contract NBSA5B/2959.

Vennell, R., 2010. Tuning turbines in a tidal channel. Journal of Fluid Mechanics 663, 253-267. doi:10.1017/S0022112010003502.

Venugopal, V., Nemalidinne, R., 2014. Marine Energy Resource Assessment for Orkney and Pentland Waters With a Coupled Wave and Tidal Flow Model, in: International Conference on Ocean, Offshore \& Arctic Engineering (OMAE) 2014. doi:10.1115/OMAE2014-24027.

Waldman, S., Genet, G., Baston, S., Side, J., 2015. Correcting for mesh size dependency in a regional model's representation of tidal turbines, in: Proceedings of the 11th European Wave \& Tidal Energy Conference (EWTEC), Nantes, France.

Wilcock, P.R., 1996. Estimating local bed shear stress from velocity observations. Water Resources Research 32, 3361-3366. doi:10.1029/96WR02277. 